edition in 1972. Thus, new knowledge of the pharmacology of, for example, opiate action, neurotransmitter substances, histamine $\mathbf{H}_{2}$-receptor and adrenoceptor blocking drugs is covered, as are outlines of general pharmacology, including the principles of pharmacokinetics and bioassay techniques.

The book is primarily directed toward the pre-clinical medical student, as well as the undergraduate in biological sciences or pharmacy; it aims to introduce the reader to pharmacological concepts and achievements. In this reviewer's view, these aims are admirably achieved and, furthermore, many a qualified doctor will find the text very helpful in refreshing knowledge of basic principles and expanding knowledge of those areas of the subject which have undergone rapid expansion in recent years. Emphasis throughout is placed on mechanisms of drug action and the relation of chemical structure to the biological activity of drugs. What better foundation for coping, in subsequent years of clinical practice, with the recurring challenge of having to appraise critically the claims made for, say, a new antimicrobial or a new antihypertensive agent.

This is an excellent paperback, at a very modest price. Those readers whose appetite has been whetted and who wish to delve more deeply into the fascinating subject matter of pharmacology, can readily do so by following-up the short reference lists given at the end of each chapter.

\section{International Classification of Procedures in Medicine}

Volume 2. Various paginations. World Health Organization, Geneva, 1978. SFr 15.00.

The World Health Organization helps 150 countries to exchange their knowledge and experience in order to achieve the highest possible levels of health throughout the world. It achieves this through several broad fields of endeavour, including international co-operation to maintain agreed standards for the classification of diseases and causes of death. This Volume 2 is an international classification of procedures in medicine. It comprises 2 main topics of radiology and of drugs. The first section comprises radiology and other applications of physics in medicine. The second section defines drugs, medicaments and biological agents. Each section has an exhaustive tabular list and alphabetical index.

This volume is intended for the libraries of radiology and therapeutics departments rather than for the postgraduate working towards higher degrees.

International Public Health between the Two World Wars The Organizational Problems

By Norman Howard-Jones. Pp. 92, illustrated. World Health Organization. Geneva, 1978. SFr 12.00.

Mindful of the achievements of the Red Cross during World War I, Henry Pomeroy Davison, Chairman of the War Council of the American Red Cross, visualized the extension of the good will and co-operation into peacetime to combat disease throughout the world. This idea was heartily endorsed by a medical conference convened by a Committee of Red Cross Societies in Cannes, France, in April 1919, which included among the 60 participants most of the eminent medical scientists, administrators and educators from throughout the world. As a result, an executive council was appointed which recommended the establishment of a health organization in connection with the new League of Nations and the foundation of a League of Red Cross Societies. However, the Office Internationale d'Hygiène Publique (OHIP) in Paris and the International Red Cross Committee in Geneva, were both, as their names imply, concerned with international health and had been established before World
War I. The functions of the two Red Cross Committees became separated, but the OHIP remained in operation after the establishment of the Health Committee of the United Nations and neither co-ordination nor co-operation was achieved.

This book, as its title suggests, is concerned with the details of the organizational problems. The author has researched most meticulously into the minutes and the records of the meetings and has highlighted the internal squabbles of the delegates and the absurd situations which arose in consequence. The book is of most value to medical and other historians and administrators, but nevertheless it is a useful supplement to the interesting and more readable book by Neville Goodman (1971). This is mainly concerned with the achievements of these organizations which seem all the more extraordinary after reading about the tensions and rivalries described by Norman Howard-Jones.

Management of War Injuries to the Jaws and Related Structures

With an appendix entitled Research in Acquired Craniofacial Disfigurement. Edited by JAMES F. Kelly. Pp. xxix +273 , illustrated. U.S. Government Printing Office (Superintendent of Documents), Washington D.C., 1978. $\$ 12.00$ (plus $25 \%$ for overseas handling) (Stock No. 008-045-00018-6).

Countries of the English-speaking world were not involved in a major conflict between the end of World War I and the commencement of World War II. It was not surprising therefore that most of the lessons learned in the earlier war had been forgotten and that Warwick, James and Fickling had to delve back into the records of The Third London General Hospital in order to produce a text book to guide those treating casualties during the early days of World War II. Only 12 years supervened between the Korean and Vietnam Wars, yet again it seems many medical and dental officers in the American forces in the field at the beginning of the second campaign were without previous battle experience. This book has been published in the hope that it will be helpful in any new conflict.

With the progressive evacuation of casualties, those engaged in early treatment do not see the long-term effects of their efforts. This state of affairs leads to the persistence of faulty methods of treatment. By tracing many patients' progress from injury to final rehabilitation, valuable lessons were learned. These are illustrated by 19 carefully selected case histories.

The first chapter reviews the history of the treatment of maxillo-facial injuries from World War I onwards. The logistics involved in the treatment of battle casualties are explained in Chapter II. Modern forms of air evacuation have made possible a revolution in patient management. These changes are explained and an account of modern treatment methods is given in 3 sections entitled Early care, Care at intermediate facilities, and Late care.

It seems that rapid evacuation by helicopter permitted the primary closure of many wounds which previously would have been treated by delayed suture. A range of investigatory procedures were available in hospitals close to the fighting which would have astonished those treating casualties at a similar time after injury even at the end of World War II. In a special section on Fluid replacement the reason for the rapid expansion of blood volume before emergency surgery by crystalloid solutions rather than plasma or blood is carefully explained.

Inevitably, errors of judgement were made. Attention is drawn to these and the ill effects of unwise actions are emphasized both in the chapter on Late care and in the Case histories. The lengthy discussion of bone grafting is particularly interesting. The application of pre-prosthetic surgery 